Article

\title{
Trimethylchitosan-Capped Silver Nanoparticles with Positive Surface Charge: Their Catalytic Activity and Antibacterial Spectrum Including Multidrug-Resistant Strains of Acinetobacter baumannii
}

\author{
Tein-Yao Chang 1,2, Cheng-Cheung Chen ${ }^{1}$, Kuang-Ming Cheng ${ }^{1}$, Chia-Yin Chin ${ }^{1}$, Yu-Hao Chen ${ }^{1}$, \\ Xin-An Chen ${ }^{1}$, Jun-Ren Sun ${ }^{3}$, Jenn-Jong Young ${ }^{1, *}$, and Tzong-Shi Chiueh ${ }^{2,3,4, *}$ \\ 1 Institute of Preventive Medicine, National Defense Medical Center, New Taipei City 23742, Taiwan; \\ teinyao@gmail.com (T.-Y.C.); 114abcd@gmail.com (C.-C.C.); ckmh@ms16.hinet.net (K.-M.C.); \\ s3300345@hotmail.com (C.-Y.C.); dt202910@hotmail.com (Y.-H.C.); h930222@gmail.com (X.-A.C.) \\ 2 Graduate Institute of Medical Science, National Defense Medical Center, Taipei City 11490, Taiwan \\ 3 Division of Clinical Pathology, Department of Pathology, Tri-Service General Hospital, Taipei City 11490, \\ Taiwan; sun3342@yahoo.com.tw \\ 4 Department of Laboratory Medicine, Linkou Chang Gung Memorial Hospital, TaoYuan City, Taiwan \\ * Correspondence: jjyoung@ms49.hinet.net (J.-J.Y.); drche0523@gmail.com (T.-S.C.); \\ Tel.: +886-2-81777038 ext. 19910 (J.-J.Y.); +886-3-3281200 ext. 5653 (T.-S.C.)
}

\begin{abstract}
We report a facile route for the green synthesis of trimethylchitosan nitrate-capped silver nanoparticles (TMCN-AgNPs) with positive surface charge. In this synthesis, silver nitrate, glucose, and trimethyl chitosan nitrate (TMCN) were used as silver precursor, reducing agent, and stabilizer, respectively. The reaction was carried out in a stirred basic aqueous medium at room temperature without the use of energy-consuming or expensive equipment. We investigated the effects of the concentrations of $\mathrm{NaOH}$, glucose, and TMCN on the particle size, zeta potential, and formation yield. The AgNPs were characterized by UV-visible spectroscopy, photon correlation spectroscopy, laser Doppler anemometry, transmission electron microscopy, X-ray diffraction, and X-ray photoelectron spectroscopy. The catalytic activity of the TMCN-AgNPs was studied by the reduction of 4-nitrophenol using $\mathrm{NaBH}_{4}$ as a reducing agent. We evaluated the antibacterial effects of the TMCN-AgNPs on Acinetobacter baumannii, Escherichia coli, Pseudomonas aeruginosa, and Staphylococcus aureus using the broth microdilution method. The results showed that both gram-positive and gram-negative bacteria were killed by the TMCN-AgNPs at very low concentration $(<6.13 \mu \mathrm{g} / \mathrm{mL})$. Moreover, the TMCN-AgNPs also showed high antibacterial activity against clinically isolated multidrug-resistant $A$. baumannii strains, and the minimum inhibitory concentration (MIC) was $\leq 12.25 \mu \mathrm{g} / \mathrm{mL}$.
\end{abstract}

Keywords: green synthesis; silver nanoparticles; trimethylchitosan nitrate; catalytic activity; antibacterial activity; multidrug-resistant Acinetobacter baumannii

\section{Introduction}

The definition of a "green process" is the manufacture of products with consideration for the source of the raw materials, energy-efficient manufacturing methods, the use of recycled materials in packaging, and the reclamation of manufacturing waste. "Green chemistry" is an area of chemistry and chemical engineering that is focused on designing products and processes that minimize the use and generation of hazardous substances, and "green industry" is a term used to describe environmentally friendly practices, or those that produce eco-conscious products.

Silver has been used for centuries as an antibacterial agent because it is natural and is capable of killing more than 650 types of disease-causing microorganisms. It has a wide range of applications in the health industry, food preservation, cosmetics, textile coatings, and environmental protection. 
Although silver ions are highly toxic to many microorganisms, they have low toxicity towards human cells. Therefore, silver ions have been used in the formulation of dental resin composites, bone cement, and coatings for medical devices [1]. Recently, nanomedicine has become a principal research field. Chemists are involved in developing green, effective, and cheap processes to prepare silver nanoparticles (AgNPs) [2]. AgNPs, nano-sized particles of metallic silver, are nontoxic, safe, inorganic particles used for preventing infections, healing wounds, and alleviating inflammation. A variety of physical or chemical methods have been developed to synthesize AgNPs, including chemical reduction, microemulsion techniques, $\gamma$-ray irradiation, laser ablation, electrochemical methods, and photochemical reduction [3]. However, most techniques involve toxic reducing agents or manufacturing methods with a high energy cost. Of these techniques, chemical reduction has potential as a green process. It can be achieved by utilizing biological systems such as fungi [4], bacteria [5], plant extracts [6], and naturally occurring saccharides or polysaccharides[7] such as glucose [8], sucrose [9], chitosan [10], starch [11], dextran [12], alginate [13], cellulose [14], chondroitin sulfate [15], hyaluronan [16] etc., as stabilizing and/or reducing agents. These green processes use water as a reaction medium and take place at room temperature without using energy-consuming or expensive equipment such as lasers [17], $\gamma$-ray [18], UV [19], or microwave apparatus [20], autoclaves [21], or electrochemical instruments [22]. Furthermore, AgNPs prepared by a green process are free from contamination from toxic reducing agents and organic solvents, and are suitable for the encapsulation of water-soluble drugs [23], genes [24], or vaccines [25] for biomedical applications. Apparently, more and more research in the field of nanomedicine with respect to AgNPs is occurring worldwide.

Chitosan (CS) is a natural renewable resource obtained from the deacetylation of chitin, and has many unique biological properties such as biodegradability, biocompatibility, nontoxicity, and antimicrobial and mucoadhesive properties. CS is a polysaccharide composed of 2-amino-2-deoxy- $\beta$-D-glucan; it contains primary amino groups that are able to confer positive charge and chemical nucleophilicity, making it very useful in pharmaceutical applications. However, CS has not been fully utilized owing to its low solubility in neutral and alkaline aqueous solutions.

Quaternary CS is a derivative of CS. It has permanent cationic charges on the polysaccharide backbone, and is therefore water-soluble over a wide range of $\mathrm{pH}$ values. Trimethylchitosan (TMC), the simplest quaternized CS, can be synthesized by reacting CS with excess methyl iodide under strongly alkaline conditions [26], or can be synthesized by treating CS with formaldehyde and formic acid to generate chitosan, followed by reaction with methyl iodide at low temperature [27]. TMC retains the original key qualities of CS but its solubility in water is substantially improved, and its mucoadhesive properties [28] and antibacterial activity [29] are enhanced.

Both gram-positive and gram-negative bacterial cell walls have a net negative charge. In gram-positive bacteria, the negative charge is provided by teichoic acids, which are linked to either the peptidoglycan or to the underlying plasma membrane. These teichoic acids are anionic owing to the presence of phosphates within their structure. Gram-negative bacteria have an outer covering of phospholipids and lipopolysaccharides. These lipopolysaccharides confer a strong negative charge on the surface of gram-negative bacteria cells [30]. Recently, the antibacterial activity of various positively or negatively charged AgNPs has been extensively evaluated [31], and the results indicated that positively charged AgNPs had higher bactericidal activity against all the microorganisms tested than negatively charged or neutral AgNPs [32, 33]. This phenomenon is mainly due to the nonspecific electrostatic interaction between positive and negative charges, which accelerates the bactericidal effect. Therefore, we suggest that the surface charge of the AgNPs is a significant factor that affects antibacterial activity.

The widespread use of antibiotics to treat infectious diseases has forced bacteria to develop resistance to them. Bacteria with increasing resistance to drugs and multidrug-resistant (MDR) bacteria have become major medical problems globally. Therefore, the discovery and development of alternatives to antibiotics have become major topics of research [34]. Several researchers have reported that AgNPs are effective not only against gram-negative and gram-positive bacteria, but also against MDR bacterial strains [35-38]. The aim of this study was to explore the effect of AgNPs 
with positively charged surfaces on gram-positive, gram-negative, and MDR bacteria. We synthesized trimethylchitosan-capped AgNPs via a green process and investigated the formation conditions based on the concentrations of the reducing agent, the stabilizer, and the base. The physical and chemical properties were characterized using UV-visible (UV-Vis) spectroscopy, photon correlation spectroscopy, laser Doppler anemometry, transmission electron microscopy (TEM), X-ray diffraction (XRD), and X-ray photoelectron spectroscopy (XPS). Furthermore, we monitored the reduction of 4-nitrophenol by $\mathrm{NaBH}_{4}$, which is a model reaction used to investigate the catalytic activity of AgNPs. We measured antibacterial activities against gram-positive and gram-negative bacteria using the broth microdilution method, and determined the minimum inhibitory concentrations (MICs) of several clinically isolated MDR Acinetobacter baumannii strains.

\section{Results and Discussion}

\subsection{Study of TMCN-AgNPs formation}

In the present studies, AgNPs were synthesized from $\mathrm{Ag}^{+}$using D-glucose as a reducing agent, and cationic polyelectrolyte TMC as a stabilizer. The experiments were performed in stirred aqueous solution at room temperature without heating or photo irradiation. Thus, this reaction process followed the principles of green synthesis.

Silver chloride $(\mathrm{AgCl})$ and silver iodide $(\mathrm{AgI})$ have very low solubility in water $\left(\mathrm{Ksp}=1.8 \times 10^{-10}\right.$ and $8.5 \times 10^{-17}$ at $25^{\circ} \mathrm{C}$, respectively). To avoid $\mathrm{AgCl}$ or $\mathrm{AgI}$ precipitation (faster reaction) before AgNPs formation (slower reaction), the chloride or iodide counter ions of the stabilizer (TMC) used in the $\mathrm{Ag}^{+}$reduction reaction must be replaced with nitrate, because silver nitrate has very high solubility in water $\left(2.56 \mathrm{~g} / \mathrm{mL}\right.$ at $\left.25^{\circ} \mathrm{C}\right)$.

It is known that the sizes, shapes, and zeta potentials of AgNPs are affected by the concentrations of the reducing agent, the stabilizer, and the base. To better understand the nucleation and growth of TMCN-AgNPs, portions of the colloid solution were taken at different time intervals and diluted 50-fold with Milli-Q water to measure SPR peaks (Fig. 1a 1d), particle sizes, and zeta potentials (Table 1). The characteristic SPR peak at around $410 \mathrm{~nm}$ confirmed the formation of AgNPs. As shown in Fig. 1a, SPR peaks have maximum intensity at the final concentration of $\mathrm{NaOH}$ equal to $10 \mathrm{mM}$. The increase in intensities of the SPR peaks indicated the increase in the concentration of AgNPs. In general, the formation rate of AgNPs is proportional to the concentration of $\mathrm{NaOH}$. However, a $\mathrm{NaOH}$ concentration higher than $10 \mathrm{mM}$ produced lower SPR intensity at $48 \mathrm{~h}$; this phenomenon may have been due to some aggregation at the high $\mathrm{NaOH}$ concentration. However, at a $\mathrm{NaOH}$ concentration below $5 \mathrm{mM}$, the particle size increased substantially owing to aggregation during nanoparticle formation (Table 1). Thus, we can conclude that the reaction rate of $\mathrm{Ag}^{+}$reduction and the particle size of the AgNPs are strongly influence by the concentration of the base. To obtain the best yield and the smallest particles, optimization of the base concentration is a priority in AgNPs synthesis.

To study the influence of TMCN concentration on AgNPs preparation, the reactions were carried out at different final concentrations of TMCN in the range $0.625-5 \mathrm{mg} / \mathrm{mL}$. According to the intensities of SPR in Fig. 1b, the concentration of TMCN had only a small influence on the formation yield of AgNPs. However, the particle size increased as the concentration increased (Table 1). These results indicate that a thicker TMCN shell is formed at higher stabilizer concentrations. 


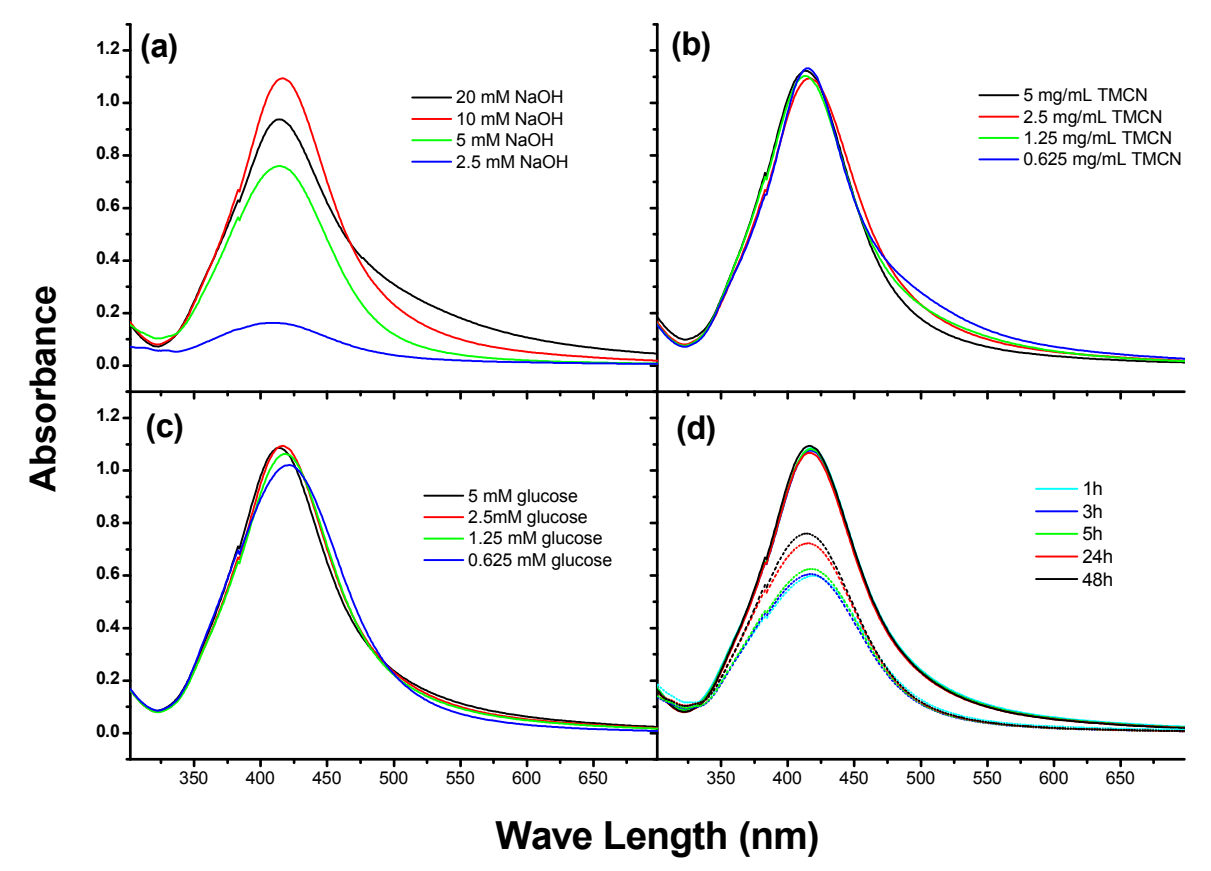

Figure 1. (a) Surface plasmon resonance (SPR) spectra of trimethylchitosan nitrate-capped silver nanoparticles (TMCN-AgNPs) synthesized at different $\mathrm{NaOH}$ concentrations $\left[\mathrm{AgNO}_{3}=5 \mathrm{mM}\right.$, glucose $=2.5 \mathrm{mM}$, trimethylchitosan nitrate $(\mathrm{TMCN})=2.5 \mathrm{mg} / \mathrm{mL}$, reaction time $=48 \mathrm{~h}]$. (b) SPR spectra of TMCN-AgNPs synthesized at different $\mathrm{TMCN}$ concentrations $\left[\mathrm{AgNO}_{3}=5 \mathrm{mM}\right.$, glucose = $2.5 \mathrm{mM}, \mathrm{NaOH}=10 \mathrm{mM}$, reaction time $=48 \mathrm{~h}$. (c) SPR spectra of TMCN-AgNPs synthesized at different glucose concentrations $\left[\mathrm{AgNO}_{3}=5 \mathrm{mM}, \mathrm{TMCN}=2.5 \mathrm{mg} / \mathrm{mL}, \mathrm{NaOH}=10 \mathrm{mM}\right.$, reaction time $=48 \mathrm{~h}$. (d) SPR spectra of TMCN-AgNPs synthesized at different reaction times $\left[\mathrm{AgNO}_{3}=5 \mathrm{mM}\right.$, glucose $=2.5 \mathrm{mM}, \mathrm{TMCN}=2.5 \mathrm{mg} / \mathrm{mL}, \mathrm{NaOH}=10 \mathrm{mM}$ (solid line) or $\mathrm{NaOH}=5 \mathrm{mM}$ (dashed line)] . All SPR spectra peaks were measured after 50-fold dilution of as-prepared colloid solution by Milli-Q water.

We carried out the reactions at various final concentrations of glucose to investigate the effect of the reducing agent. In Fig. 1c, the intensities of SPR increased as the concentration of glucose increased, which represents a higher AgNP formation yield obtained at the higher glucose concentration in the range $0.625-5 \mathrm{mM}$. At the same time, the small blue shift of the SPR peaks in Fig. 1c indicates a slight decrease in the particle size [15] as the glucose concentration increased, which is consistent with the results observed using the dynamic light scattering (DLS) method (Table 1).

Fig. 1d shows the SPR peaks measured at the different time intervals for two $\mathrm{NaOH}$ concentrations. Apparently, at a $\mathrm{NaOH}$ concentration of $10 \mathrm{mM}$, the SPR intensity reached a maximum and remained constant at all time intervals, which indicates that the reduction of $\mathrm{Ag}^{+}$ was completed within $1 \mathrm{~h}$ and no aggregation occurred. At a $\mathrm{NaOH}$ concentration of $5 \mathrm{mM}$, reduction progressed more slowly, and the SPR intensity apparently increased as the reaction progressed. 
Table 1. The effect of the final concentrations of glucose, trimethyl chitosan nitrate (TMCN), and $\mathrm{NaOH}$ on particle size and surface charge of trimethyl chitosan nitrate-capped silver nanoparticles (TMCN-AgNPs)

\begin{tabular}{|c|c|c|c|c|c|}
\hline \multicolumn{4}{|c|}{ Final concentration } & \multirow{2}{*}{$\begin{array}{c}\text { Size }^{*} \\
\text { Z-average } \\
(\mathrm{nm})\end{array}$} & \multirow{2}{*}{$\begin{array}{c}\text { Zeta potential }^{* *} \\
\mathrm{mV}\end{array}$} \\
\hline $\begin{array}{l}\mathrm{AgNO}_{3} \\
(\mathrm{mM})\end{array}$ & $\begin{array}{c}\text { Glucose } \\
(\mathrm{mM})\end{array}$ & $\begin{array}{c}\text { TMCN } \\
(\mathrm{mg} / \mathrm{mL})\end{array}$ & $\begin{array}{c}\mathrm{NaOH} \\
(\mathrm{mM})\end{array}$ & & \\
\hline 5 & 5 & 2.5 & 10 & $93.4 \pm 3.6$ & 58.2 \\
\hline 5 & 2.5 & 2.5 & 10 & $98.3 \pm 4.3$ & 53.7 \\
\hline 5 & 1.25 & 2.5 & 10 & $100.0 \pm 4.4$ & 51.8 \\
\hline 5 & 0.625 & 2.5 & 10 & $112.6 \pm 2.2$ & 63.1 \\
\hline 5 & 2.5 & 5 & 10 & $102.4 \pm 2.8$ & 52.9 \\
\hline 5 & 2.5 & 1.25 & 10 & $81.2 \pm 3.6$ & 41.7 \\
\hline 5 & 2.5 & 0.625 & 10 & $70.8 \pm 8.3$ & 41.9 \\
\hline 5 & 2.5 & 2.5 & 20 & $93.4 \pm 3.3$ & 48.4 \\
\hline 5 & 2.5 & 2.5 & 5 & $79.8 \pm 10.3$ & 59.1 \\
\hline 5 & 2.5 & 2.5 & 2.5 & $179.9 \pm 109.0$ & 41.9 \\
\hline
\end{tabular}

* Average size measured by dynamic light scattering (DLS) method (50-fold dilution).

**Zeta potential measured after dialysis of TMCN-AgNPs by laser Doppler anemometry method (50-fold dilution).

\subsection{Characterization of TMCN-AgNPs}

TMCN-AgNPs were further characterized by TEM, XRD, and XPS. The TEM images of the purified TMCN-AgNPs are shown in Fig. 2A. The nanoparticles were well dispersed, well-defined, round, and mostly $<60 \mathrm{~nm}$ in diameter. The particle size measured using TEM is smaller than the Z-average diameter $(81.2 \mathrm{~nm})$ obtained from DLS. This phenomenon may have arisen because the Z-average was calculated from the intensity size distribution, which is proportional to the sixth power of the radius of the particles; thus the DLS method will have emphasized the effect of larger particles and produced a larger particle size calculation.

$\mathrm{XRD}$ is very useful for determining the crystal structure of metal nanoparticles. The XRD pattern of the TMCN-AgNPs is shown in Fig. 2b. The observed $2 \theta$ values at 38.2, 44.4, 64.6, and 77.6 correspond to the (111), (200), (220), and (311) reflections, respectively, which can be indexed as the band for the fcc structure of AgNPs. Therefore, the XRD pattern demonstrated the crystalline nature of the TMCN-AgNPs.

Elementary XPS analysis can provide further information regarding the structure and chemical state of AgNPs. The survey spectrum indicated the presence of carbon, oxygen, and silver (data not shown). The XPS spectrum of silver atoms is depicted in Fig. 2c. There are two peaks located at the binding energies of 372.4 and $378.4 \mathrm{eV}$, which correspond to the emission of $3 \mathrm{~d}$ photoelectrons, i.e., $\operatorname{Ag} 3 \mathrm{~d}_{5 / 2}$ and $\mathrm{Ag} 3 \mathrm{~d}_{3 / 2}$, respectively.

\subsection{Catalytic reduction of $4-N P$}

Using noble metal NPs as catalysts has become one of the model reactions for evaluating the catalytic activity of various metal nanoparticles capped with different stabilizers [39]. Although the reduction of $4-\mathrm{NP}$ by $\mathrm{NaBH}_{4}$ is a thermodynamically feasible process, it is kinetically restricted in the 
absence of a catalyst. The peak at $400 \mathrm{~nm}$ indicated that a 4-nitrophenolate anion was formed upon addition of $\mathrm{NaBH}_{4}$. The catalytic reduction of 4-NP can easily be used to monitor the reactant 4-nitrophenolate anion through spectrophotometry. Fig. 3a shows that after TMCN-AgNPs were added, there was a significant decrease in the intensity of the absorbance at $400 \mathrm{~nm}$ as the reaction progressed.

(a)

(b)

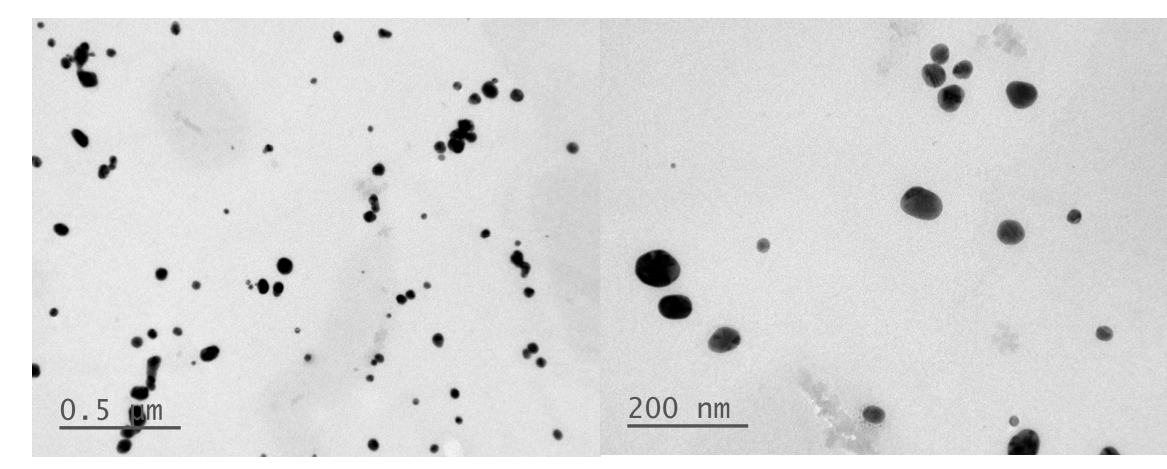

(c)
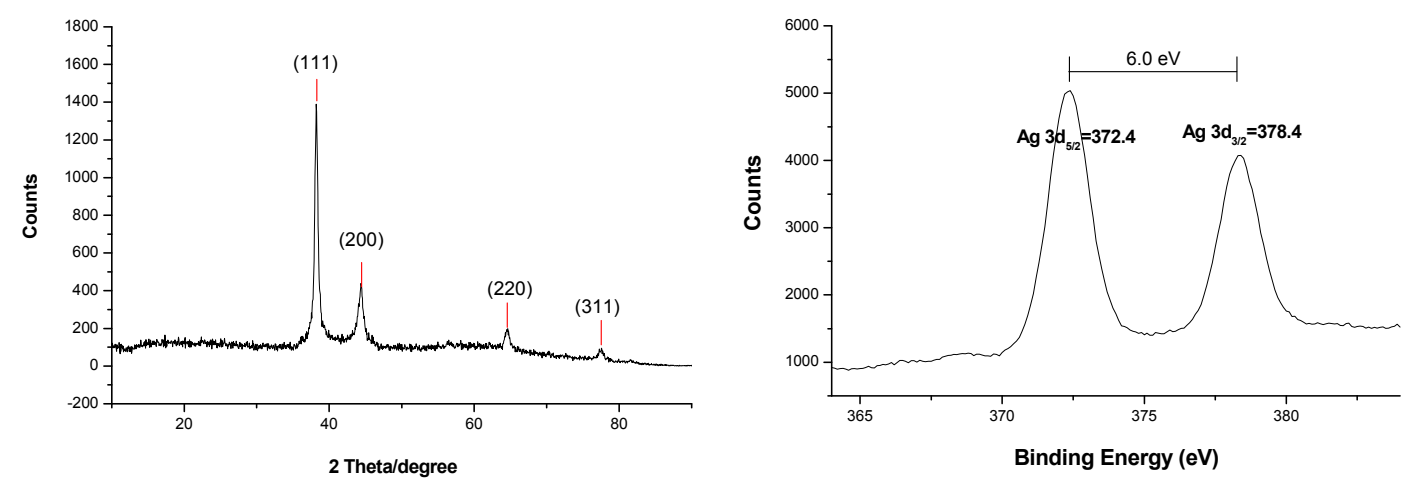

Figure 2. (a) Transmission electron microscopy (TEM) image of trimethyl chitosan nitrate-capped silver nanoparticles (TMCN-AgNPs). (b) X-ray diffraction (XRD) pattern of TMCN-AgNPs confirmed the formation of fcc crystalline structure. (c) X-ray photoelectron spectroscopy (XPS) elemental composition analysis of TMCN-AgNPs.

To gain a closer insight into the catalytic activity of TMCN-AgNPs in the reduction of 4-NP, some kinetic parameters should be evaluated. From a kinetic perspective, the reduction rate (v) of $4-\mathrm{NP}$ by $\mathrm{NaBH}_{4}$ can be described by the following equation (in a large excess of $\mathrm{NaBH}_{4}$ and therefore $\left.\left[\mathrm{NaBH}_{4}\right] »[4-\mathrm{NP}]\right)$ :

$$
\mathrm{v}=-\frac{\mathrm{d}[4-\mathrm{NP}]}{\mathrm{dt}}=-k \times d t=k \times[4-\mathrm{NP}]^{\mathrm{n}}
$$

where $\mathrm{k}$ is the rate constant; [4-NP] is the concentration of 4-NP, and $\mathrm{n}$ is the reaction order.

However, the dependence of absorbance A on concentration C can be represented by the BeerLambert equation:

$$
\mathrm{A}=\varepsilon(\lambda) 1 \mathrm{C}
$$

where 1 is the path length, and $\varepsilon(\lambda)$ is the molar absorption coefficient. 

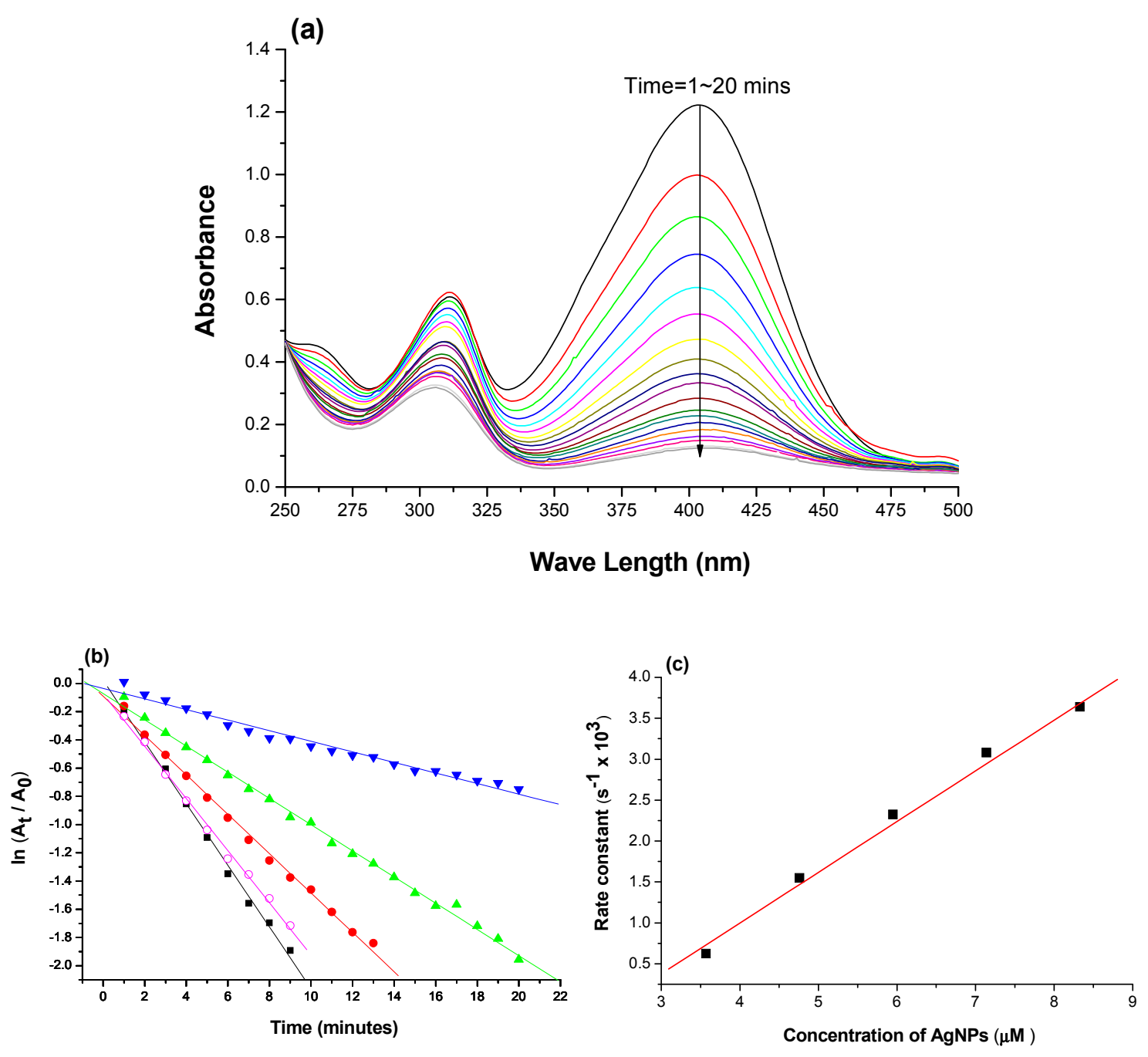

Figure 3. (a) Time dependent UV-vis spectra for the catalytic reduction of 4-nitrophenol (4-NP) by $\mathrm{NaBH}_{4}$ in the presence of trimethyl chitosan nitrate-capped silver nanoparticles (TMCN-AgNPs). (b) Plot of $\ln \left(\mathrm{A}_{t} / \mathrm{A}_{\mathrm{o}}\right)$ against time for first-order reduction kinetics of $4-\mathrm{NP}$ by $\mathrm{NaBH}_{4}$ in the presence of different concentrations of AgNPs. [ $\boldsymbol{\square}=8.33 \mu \mathrm{M} ; \mathrm{O}=7.14 \mu \mathrm{M} ; \bullet=5.95 \mu \mathrm{M} ; \boldsymbol{\Lambda}=4.76 \mu \mathrm{M} ; \boldsymbol{\nabla}=3.57$ $\mu \mathrm{M}$;] (c) The plot of rate constant versus catalyst concentration for 4 -NP reduction $(\mathrm{Y}=0.6354 \mathrm{X}$ 1.5372; $\left.\mathrm{R}^{2}=0.9928\right)$.

Because AgNPs have strong SPR absorbance at $420 \mathrm{~nm}$, the linear correlation between A and C is valid only for very low concentrations of AgNPs. In our case, because the concentration of AgNPs was approximately $10^{-6} \mathrm{M}$, this criterion was fulfilled; the Beer-Lambert equation is therefore applicable to equation (3) and can be rearranged for convenient monitoring by spectrophotometry measurements:

$$
\ln \frac{[4-N P]_{t}}{[4-N P]_{0}}=\ln \frac{A_{t}}{\mathrm{~A}_{0}}=-k \times d t
$$

where $[4-\mathrm{NP}]_{0}$ and $[4-\mathrm{NP}]_{t}$ represent the concentration of 4-NP at the initial time and at a moment $\mathrm{t}$ during the reaction, respectively. $A_{o}$ and $A_{t}$ are the absorbance values at the respective moments. Apparently, the linear logarithmic $\ln \left(\mathrm{A}_{\mathrm{t}} / \mathrm{A}_{\mathrm{o}}\right)$ versus time plot confirms that the 4-NP catalytic 
reduction reaction obeys first-order kinetics (Fig. 3b). The 4-NP reduction was studied with various catalyst concentrations and the first-order reaction rate constants $(\mathrm{k})$ are compared in Table 2 . In all cases, the curves showed excellent linear correlation $\left(\mathrm{R}^{2}>0.97\right)$. We found that the rate constant increased with an increasing amount of catalyst. Fig. 3c shows that the reaction rate generally increased linearly with the amount of catalyst.

Table 2. Rate constants (kobs) for catalytic reduction of 4-nitrophenol by $\mathrm{NaBH}_{4}$ depend on the concentration of trimethylchitosan nitrate-capped silver nanoparticles (TMCN-AgNPs)

\begin{tabular}{cccc}
\hline $\begin{array}{c}\text { AgNPs } \\
(\mu \mathrm{M})\end{array}$ & $\begin{array}{c}\text { kobs } \\
\left(\mathrm{min}^{-1}\right)\end{array}$ & $\begin{array}{c}\text { kobs } \\
\left(\mathrm{s}^{-1}\right)\end{array}$ & $\mathrm{R}^{2}$ \\
\hline 8.33 & 0.2184 & $3.64 \times 10^{-3}$ & 0.997 \\
7.14 & 0.1848 & $3.08 \times 10^{-3}$ & 0.996 \\
5.95 & 0.1395 & $2.33 \times 10^{-3}$ & 0.996 \\
4.76 & 0.0929 & $1.55 \times 10^{-3}$ & 0.997 \\
3.57 & 0.0375 & $0.63 \times 10^{-3}$ & 0.976 \\
\hline
\end{tabular}

*Final concentration of $\mathrm{Ag}^{0}$ in the reaction mixture

\subsection{Antibacterial activities of TMCN-AgNPS}

First, we tested the antibacterial activity of the TMCN-AgNPs against three gram-negative bacteria and one gram-positive bacterium using the broth microdilution method. Broth microdilution is frequently used to test the susceptibility of bacteria to antibiotics, and its accuracy is comparable to the agar dilution test $[40,41]$. As shown in Fig. 4A, the broths containing E. coli and S. aureus became cloudy at a 128-fold dilution of TMCN-AgNPs, and the broths containing A. baumannii and P. aeruginosa became cloudy at 256-fold dilution. Thus, the calculated MIC of E. coli and S. aureus is $6.13 \mu \mathrm{g} / \mathrm{mL}$, and the MIC of A. baumannii and P. aeruginosa is $3.06 \mu \mathrm{g} / \mathrm{mL}$ (Table 3).

As well as by observation, the turbidity can be assessed using a spectrophotometer to quantify bacteria. This technique is based on the fact that the broth becomes increasingly turbid as the number of bacteria in the broth increases. The light passing through a sample is scattered by the microorganisms contained in it (such as bacteria, fungi, and yeast), so the turbidity is proportional to the number of micro-organisms. The turbidity can be detected using a spectrophotometer by measurement of the absorbance at $600 \mathrm{~nm}$, and the optical density (OD) is directly proportional to the number of bacteria. As shown in Fig. 4B, the OD600 values remained constant for $24 \mathrm{~h}$ at 64 -fold dilution or below. This means that the TMCN-AgNPs inhibited the growth of all four species of bacteria at a concentration of $6.13 \mu \mathrm{g} / \mathrm{mL}$. Furthermore, TMCN-AgNPs inhibit A. baumannii and P. aeruginosa growth at a concentration of $3.06 \mu \mathrm{g} / \mathrm{mL}$ (128-fold dilution). These results are consistent with the previous visual observation. All four species of bacteria were able to grow in the broth at the 256-fold and 512-fold dilutions of TMCN-Ag. However, the growth declined significantly according to growth curve monitoring. TMCN $(2.5 \mathrm{mg} / \mathrm{mL})$ also showed a little bacterial inhibition activity, and the bacteria started to grow only after $12 \mathrm{~h}$ incubation at $37^{\circ} \mathrm{C}$. The growth of all four species of bacteria was inhibited by kanamycin at a concentration of $64 \mu \mathrm{g} / \mathrm{mL}$. 
(a)

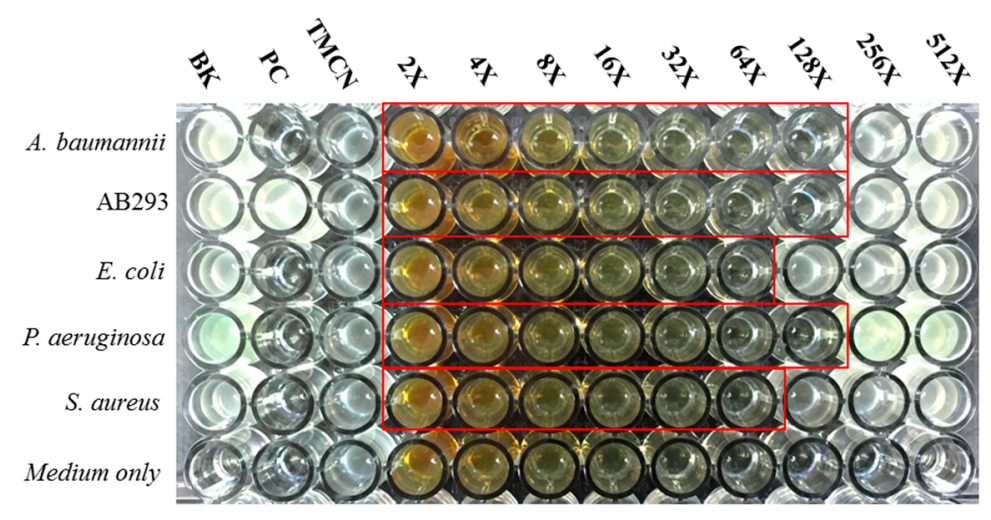

(b)

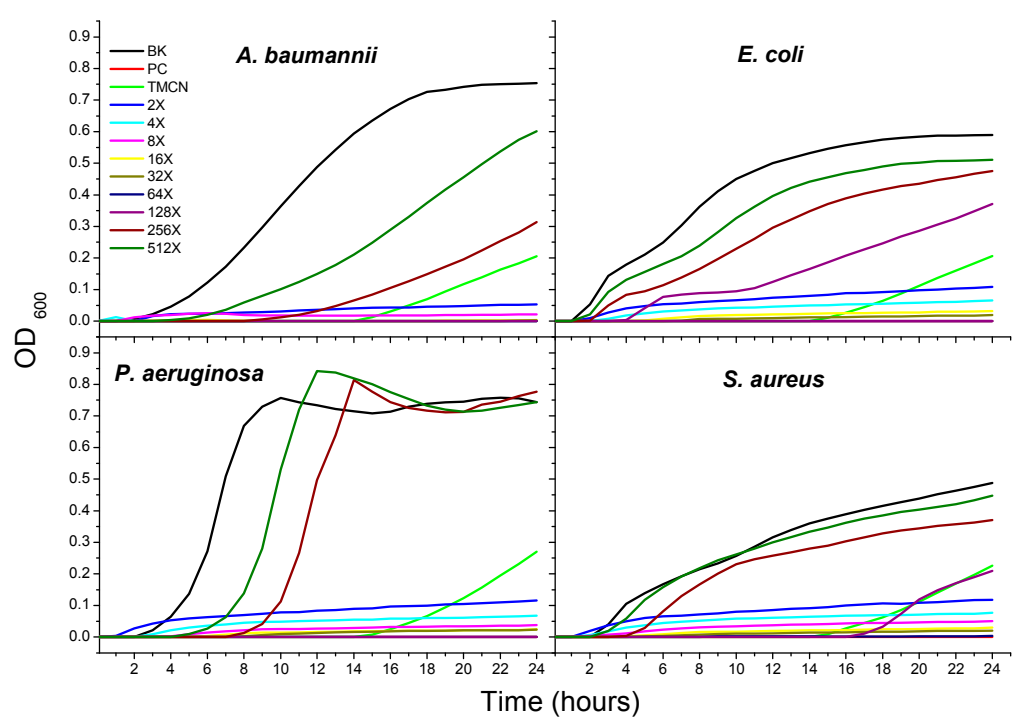

Figure 4. (a) 96-well microtiter plate used for broth microdilution with trimethyl chitosan nitrate-capped silver nanoparticles (TMCN-AgNPs) against A. baumannii (row A), E. coli (row C), P. aeruginosa (row D), and S. aureus (row E), and using MH medium (column 1) and kanamycin (column 2) as blank and positive control, respectively. Columns 4 to 12 were eight successive twofold dilutions of TMCN-AgNPs ( $196 \mu \mathrm{g} / \mathrm{mL}$ to $0.752 \mu \mathrm{g} / \mathrm{mL}$ of AgNPs). The plate was incubated at $37^{\circ} \mathrm{C}$ for $24 \mathrm{~h}$. (b) Microbial growth kinetics of each bacterium in the presence of different concentration of TMCN-AgNPs via eight successive twofold dilutions. OD600 values were measured every $20 \mathrm{~min}$ until 24 h. (BK: MH medium, PC: 64 g/mL kanamycin, TMCN: 2.5 mg/mL TMCN).

Recently, A. baumannii has become a significant opportunistic pathogen of nosocomial infection in Taiwan, especially in ICU [42]. However, the real challenge is the acquisition of MDR in hospital. Infections caused by MDR bacteria lead to longer periods of hospitalization with a lower chance of treatment. Table S1 (see supplementary material) shows the antibiotic susceptibility profile of clinically isolated MDR strains of A. baumannii (MDRAB) [43]. All MDRAB are resistant to more than three commonly used antibiotics including tigecycline, a third-generation broad-spectrum antibiotic, which means that MDRAB-infected patients have limited therapeutic options. Figure 5 shows the broth microdilution test results for MDRAB. In most cases except for AB166, the TMCN-AgNPs inhibited the growth of MDRAB at a concentration of $6.13 \mu \mathrm{g} / \mathrm{mL}$ or below (Table 3). The MIC of AB166 was $12.25 \mu \mathrm{g} / \mathrm{mL}$. It is our understanding that the mechanisms of bacterial 
resistance to antibiotics, including the prevention of access to drug targets, change with the structure and protection of antibiotic targets and the direct modification or inactivation of antibiotics. The antibacterial activity of AgNPs on MDRAB may be due to antibacterial mechanisms other than those associated with regular antibiotics. Although the antibacterial mechanisms of AgNPs are not fully understood, some hypotheses have been proposed. Kim et al. proposed that AgNPs adhering to the bacterial cell wall cause the formation of pits, which sequentially lead to permeability loss and the death of the bacteria [44]. Another possible mechanism is that AgNPs release silver ions or free radicals, leading to bacterial death. Our data suggest that TMCN-AgNPs have an antibiotic effect on MDRAB and might have a synergistic effect when used in combination with other antibiotics [45] for the treatment of other MDR bacteria.

Table 3. Antibacterial susceptibility test of trimethyl chitosan nitrate-capped silver nanoparticles (TMCN-AgNPs) by broth microdilution method

\begin{tabular}{llc}
\hline \multicolumn{1}{c}{ Strains } & Bacteria type & MIC* end point \\
\hline A. baumannii ATCC 19606 & Gram-negative & $3.06 \mu \mathrm{g} / \mathrm{mL}$ \\
E. coli ATCC 11775 & Gram-negative & $6.13 \mu \mathrm{g} / \mathrm{mL}$ \\
P. aeruginosa ATCC 10145 & Gram-negative & $3.06 \mu \mathrm{g} / \mathrm{mL}$ \\
S. aureus ATCC 12600 & Gram-positive & $6.13 \mu \mathrm{g} / \mathrm{mL}$ \\
AB86 clinically isolated strain & MDR gram-negative & $6.13 \mu \mathrm{g} / \mathrm{mL}$ \\
AB89 clinically isolated strain & MDR gram-negative & $6.13 \mu \mathrm{g} / \mathrm{mL}$ \\
AB166 clinically isolated strain & MDR gram-negative & $12.25 \mu \mathrm{g} / \mathrm{mL}$ \\
AB173 clinically isolated strain & MDR gram-negative & $3.06 \mu \mathrm{g} / \mathrm{mL}$ \\
AB260 clinically isolated strain & MDR gram-negative & $6.13 \mu \mathrm{g} / \mathrm{mL}$ \\
AB293 clinically isolated strain & MDR gram-negative & $3.06 \mu \mathrm{g} / \mathrm{mL}$ \\
AB388 clinically isolated strain & MDR gram-negative & $6.13 \mu \mathrm{g} / \mathrm{mL}$ \\
\hline
\end{tabular}

*Based on the weight of AgNPs

**MDR: multidrug-resistant

(a)

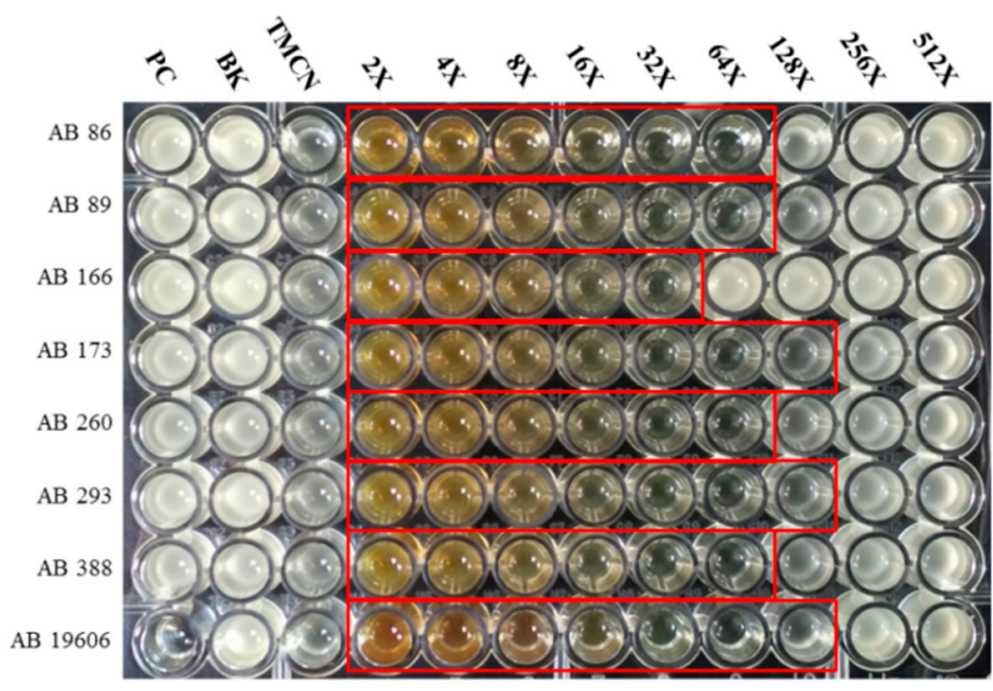


(b)

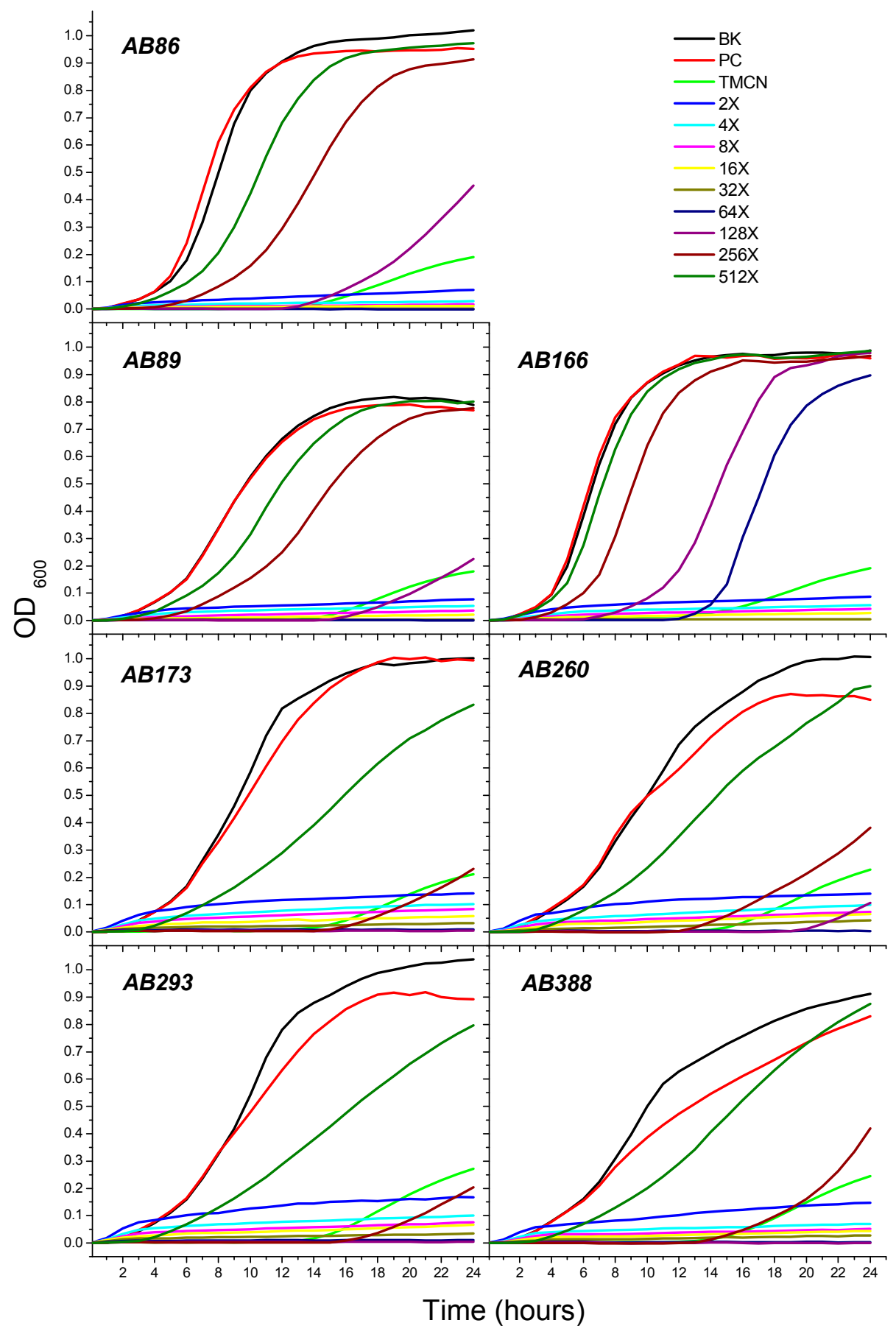

Figure 5. (A) 96-well microtiter plate used for broth microdilution with trimethyl chitosan nitrate-capped silver nanoparticles (TMCN-AgNPs) against seven MDR strains of A. baumannii (row A-G), and normal A. baumannii 19606 (row H). MH medium (column 1) and kanamycin (column 2) was used as blank and positive control, respectively. Columns 4 to 12 were eight successive twofold dilutions of TMCN-AgNPs $\left(196 \mu \mathrm{g} / \mathrm{mL}\right.$ to $0.752 \mu \mathrm{g} / \mathrm{mL}$ of AgNPs). The plate was incubated at $37^{\circ} \mathrm{C}$ for $24 \mathrm{~h}$. (B) Microbial growth kinetics of seven MDR strains of A. baumannii in the presence of different concentration of TMCN-AgNPs via eight successive twofold dilutions. OD600 values were measured every 20 min until 24 h. (BK: MH medium, PC: $64 \mu \mathrm{g} / \mathrm{mL}$ kanamycin, TMCN: $2.5 \mathrm{mg} / \mathrm{mL} \mathrm{TMCN})$. 


\section{Materials and Methods}

\subsection{Materials}

Chitosan (viscosity: $3.6 \mathrm{mPa} \cdot \mathrm{s}$ (5 g/L), degree of deacetylation (DD): 93.8\%) was purchased from Wako Pure Chemical Industries, Ltd. (Osaka, Japan). Methyl iodide, silver nitrate, D(+)-glucose, sodium nitrate, and sodium hydroxide were purchased from Merck (Darmstadt, Germany). Sodium iodide was obtained from Sigma-Aldrich (St. Louis, MO, USA). Ultra-pure water was obtained with Milli-Q equipment (Millipore, Billerica, MA, USA). A. baumannii MDR strains were identified from clinical samples obtained from the Tri-Service General Hospital of Taiwan and the antibiotic susceptibility profiles were determined using a Vitek2 system (bioMérieux, USA) following the standard procedure. An MDR strain was defined as one that was resistant to at least three antimicrobial agents more than the natural strain.

\subsection{Trimethyl chitosan nitrate (TMCN) synthesis}

Trimethyl chitosan iodide (TMCI) and trimethyl chitosan chloride (TMCC) were synthesized via a two-step methylation method according to our previously described procedure [26]. Briefly, in

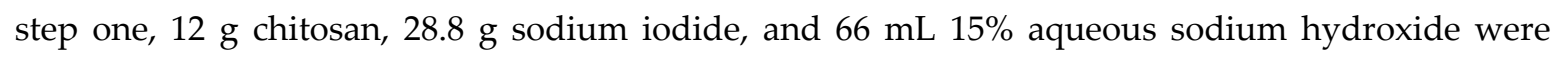
mixed in $250 \mathrm{~mL} \mathrm{~N}$-methylpyrrolidone and heated at $60^{\circ} \mathrm{C}$. Next, $69 \mathrm{~mL}$ methyl iodide was added using an addition-funnel, and the reactants were heated at $60^{\circ} \mathrm{C}$ for $90 \mathrm{~min}$. The polymer was collected via precipitation with ethanol and isolated via centrifugation. The final product was washed with acetone on a sinter glass filter and dried under vacuum. In step two, the polymer obtained in step one was mixed with $28.8 \mathrm{~g}$ sodium iodide and $66 \mathrm{~mL} \mathrm{15 \%}$ sodium hydroxide in 250 $\mathrm{mL} N$-methylpyrrolidone at $60^{\circ} \mathrm{C}$. Methyl iodide $(42 \mathrm{~mL})$ was added to the mixture during rapid stirring, and the reaction was carried out with a condenser at $60^{\circ} \mathrm{C}$ for $60 \mathrm{~min}$. An additional $12 \mathrm{~mL}$ methyl iodide and $3.6 \mathrm{~g}$ sodium hydroxide pellets were added, and the stirring was continued for 1 h. Next, TMCI was precipitated, washed, and dried as described above. For the ion-exchange step, the TMCI prepared above was dissolved in $240 \mathrm{~mL} \mathrm{10 \%} \mathrm{(w/v)} \mathrm{sodium} \mathrm{chloride} \mathrm{solution} \mathrm{(to} \mathrm{exchange}$ the iodide ion with chloride) and precipitated with ethanol. TMCC was repeatedly dissolved in 240 $\mathrm{mL} 10 \%(\mathrm{w} / \mathrm{v})$ sodium chloride solution and precipitated with ethanol to remove the remaining iodide ions. The final products were dried in a vacuum chamber for at least $12 \mathrm{~h}$ before further characterization.

TMCN was prepared from TMCC or TMCI via a similar ion-exchange step. Briefly, TMCC or TMCI were dissolved in $240 \mathrm{~mL} \mathrm{10 \%} \mathrm{(w/v)} \mathrm{sodium} \mathrm{nitrate} \mathrm{solution} \mathrm{(to} \mathrm{exchange} \mathrm{the} \mathrm{chloride} \mathrm{or}$ iodide ion with nitrate) and precipitated with ethanol. The products were repeatedly dissolved in $140 \mathrm{~mL} \mathrm{10 \%} \mathrm{(w/v)} \mathrm{sodium} \mathrm{nitrate} \mathrm{solution} \mathrm{and} \mathrm{dialyzed} \mathrm{against} \mathrm{water} \mathrm{using} \mathrm{a} \mathrm{Dialysis} \mathrm{Cassette}$ (Slide-A-Lyzer $^{\circledR}$, G2, 2000 MWCO, $70 \mathrm{~mL}$ capacity). The final product was lyophilized.

To determine the degree of quaternization of the TMCN polymers, we obtained ${ }^{1} \mathrm{H}$ nuclear magnetic resonance (NMR) spectra using an NMR spectrometer (AV-500, Bruker, Switzerland) by dissolving samples of the polymers in deuterium oxide with suppression of the water peak. The degree of quaternization was calculated from the ${ }^{1} \mathrm{H}$ NMR data (see supplementary material Fig. S1) according to equation 4 :

$$
\% \mathrm{DQ}=\left\{\left[\left(\mathrm{CH}_{3}\right)_{3}\right] /\left[\mathrm{COCH}_{3}\right] \times 1 / 3 \times(1-\% \mathrm{DD})\right\}
$$


where $\% \mathrm{DQ}$ is the degree of quaternization as a percentage, \%DD is degree of deacetylation, the $\left[\left(\mathrm{CH}_{3}\right)_{3}\right]$ is the integral of the chemical shift of the trimethyl amino group at $3.3 \mathrm{ppm}$, and $\left[\mathrm{COCH}_{3}\right]$ is the integral of the singlet peak at $2.4 \mathrm{ppm}$.

\subsection{Green synthesis of TMCN-capped silver nanoparticles (TMCN-AgNPs)}

The TMCN-AgNPs were synthesized by the reduction of $\mathrm{Ag}^{+}$ions in an alkaline aqueous medium using glucose as a reducing agent and TMCN as a stabilizing agent. In a typical preparation process, an aqueous solution of silver nitrate was added dropwise to an aqueous solution of TMCN, glucose, and $\mathrm{NaOH}$ at room temperature while stirring. The mixture was stirred continuously for 2 days. At predetermined intervals $(1,3,5,24$, and $48 \mathrm{~h})$, portions of the reaction mixture were immediately taken and diluted 50-fold to measure the surface plasmon resonance (SPR), size, and zeta potential. Table 1 summarizes the synthesis conditions used to prepare the TMCN-AgNPs. The dependence of SPR, particle size, and zeta potential on the reaction time and the concentrations of glucose, TMCN, and $\mathrm{NaOH}$ was also studied in detail. After the reaction, the resulting dispersions were placed under ambient conditions for several weeks. We found that the aqueous solution of AgNPs was stable for more than two months in the as-prepared solution at room temperature.

The excess reactants remaining in suspension were dialyzed against water using a Dialysis Cassette (Slide-A-Lyzer ${ }^{\circledR}$, G2, 2000 MWCO). The purified TMCN-AgNPs were used to record TEM images, and to measure catalytic, antibacterial, and cytotoxic activities.

\subsection{Physicochemical characterization of TMCN-AgNPS}

UV-vis absorption spectra were recorded on a Perkin Elmer Lambda 35 spectrophotometer (PerkinElmer, Waltham, MA, USA), scanning from 300 to $700 \mathrm{~nm}$. Samples were run in disposable 1.5-mL plastic cuvettes. Milli-Q water was used in the reference cell. Concentrated samples were diluted 50-fold with Milli-Q water before detection. The measurements were carried out immediately after the predetermined time intervals over the duration of this study.

The particle size was characterized by photon correlation spectroscopy (Zetasizer Nano-ZS; Malvern Instruments, UK). The instrument contains a $4 \mathrm{~mW}$ He-Ne laser that operates at a wavelength of $633 \mathrm{~nm}$, and an avalanche photodiode (APD) detector. The scattered light was detected at an angel of $173^{\circ}$. Raw data were subsequently correlated to the mean hydrodynamic size

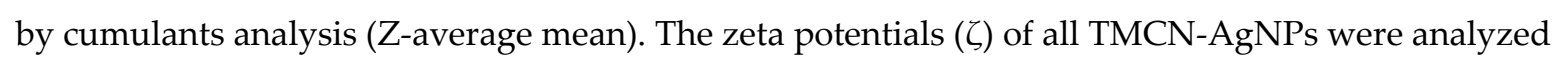
using laser Doppler anemometry (Zetasizer Nano-ZS; Malvern Instruments, UK).

The morphology of the TMCN-AgNPs following purification according to the procedure described previously was examined using a JEOL JEM-1200 EXII transmission electron microscope (JEOL, Tokyo, Japan). A typical method for preparing TEM samples was as follows: one drop of the TMCN-AgNPs suspension was deposited on a 200-mesh Formvar/carbon-coated copper grid, and excess solution was removed by wicking with filter paper to avoid particle aggregation. The images were examined by TEM at $80 \mathrm{kV}$.

The crystalline structure of the TMCN-AgNPs was examined by X-ray diffraction (XRD), which was carried out using a Bruker D2 Phaser powder diffractometer (Karlsruhe, Germany) operated with a $\mathrm{Cu} \mathrm{K} \alpha$ radiation source filtered with a graphite monochromator $(0.154 \mathrm{~nm})$. X-rays were generated at $30 \mathrm{kV}$ and $10 \mathrm{~mA}$. The XRD scans were recorded at $2 \theta$ from 10 to $90^{\circ}$ with a scan rate of $0.05 \%$. 0.5 . 
The X-ray photoelectron spectra were collected using a VG-Scientific ESCALAB 250 instrument. The elemental analysis was conducted using a pass energy of $20 \mathrm{eV}$ for individuals and $160 \mathrm{eV}$ for the survey. $\mathrm{A} 1 \mathrm{~K} \alpha$ radiation at $1486.6 \mathrm{eV}$ was used and the peak positions were calibrated internally to the $\mathrm{C}_{1 \mathrm{~s}}$ peaks at $284.6 \mathrm{eV}$. A colloidal sample was deposited on a silicon substrate and dried in a vacuum chamber at $110^{\circ} \mathrm{C}$ for XPS signal measurement. The operating power used was $300 \mathrm{~W}$, and the scan rate was $0.1 \mathrm{eV} / 150 \mathrm{~ms}$.

\subsection{Catalytic activity assays}

The reduction of 4-nitrophenol (4-NP) by $\mathrm{NaBH}_{4}$ was used as a model reaction to investigate the catalytic activity of the TMCN-AgNPs. The catalytic reaction was carried out in a standard quartz cell with a 1-cm path length and a volume of $3.2 \mathrm{~mL}$. To study the effect of catalyst concentration, the final concentration of AgNPs was varied over the range 3.57-8.33 $\mu \mathrm{M}$, maintaining the final concentration of $4-\mathrm{NP}$ at $0.1 \mathrm{mM}$ and that of $\mathrm{NaBH}_{4}$ at $0.1 \mathrm{M}$. After the catalyst was added, we monitored the reaction by observing the absorbance peak of the nitrophenolate anion at $400 \mathrm{~nm}$ by UV-Vis spectrophotometry for up to 20 mins. The continuous hydrogen generation by $\mathrm{NaBH}_{4}$ kept the solution mixed throughout the recording time.

\subsection{Antibacterial susceptibility test}

The antibacterial activity of the TMCN-AgNPs was tested using the broth microdilution method. Four ATCC bacterial strains (Acinetobacter baumannii [ATCC19606], Escherichia coli [ATCC11775], Pseudomonas aeruginosa [ATCC10145], and Staphylococcus aureus [ATCC12600]), and seven clinically isolated MDR strains of A. baumannii (AB293) were used for this study. We followed the Clinical and Laboratory Standards Institute (CLSI) standardized method for broth microdilution with some modifications [46]. Briefly, bacteria were subcultured on Luria-Bertani (LB) agar plates (Lab M, UK) overnight and grown in Müller-Hinton (MH) broth (Lab M, UK) for $24 \mathrm{~h}$. The turbidity of the bacterial suspension was adjusted to level 0.5 of the McFarland scale. MICs were determined in 96-well round-bottom microtiter plates (Thermo Fisher, USA). MH medium (100 $\mu \mathrm{L})$, kanamycin (128 $\mu \mathrm{L} / \mathrm{mL}$, Sigma-Aldrich, USA), and TMCN $(5 \mathrm{mg} / \mathrm{mL})$ were added from column 1 to column 3 as background blank, positive control, and reference, respectively. Then, $100 \mu \mathrm{L}$ suspension solutions of TMCN-AgNPs ( $385 \mathrm{mg} / \mathrm{L}$ based on silver weight) were added from column 4 to column 5 , and eight successive twofold dilutions were made using MH medium from column 5 to column 12 . Next, $100 \mu \mathrm{L}$ bacterial suspensions were dispensed into the well from column 1 to column 12 . The plate was incubated at $37^{\circ} \mathrm{C}$ for $24 \mathrm{~h}$. The growth curve of the bacteria was monitored by optical density at $600 \mathrm{~nm}\left(\mathrm{OD}_{600}\right)$ and measured every 20 min using Infinite ${ }^{\circledR} 200$ PRO multimode microplate readers (Tecan, Switzerland). MICs were determined as the lowest concentration that inhibited the visible growth of the bacteria.

\section{Conclusions}

This study demonstrated that high concentrations of TMCN-AgNPs can be prepared in an environmentally friendly manner by the chemical reduction of silver ions in a stirred aqueous medium at room temperature without heating or photo-irradiation. AgNPs coated with cationic TMCN have a positive surface charge and display high storage stability at the room temperature. We found that the TMCN-AgNPs with positively charged surfaces killed gram-positive, gram-negative, and A. baumannii MDR strains at very low concentrations. The broad-spectrum antibacterial activities of TMCN-AgNPs could be translated into clinical therapy, especially considering the shortage of new antibiotics for killing MDR bacteria. 
Supplementary Materials: The following are available online at www.mdpi.com/link, Figure S1: NMR spectra of Trimethylchitosan Nitrate (TMCN), Figure S2: FTIR spectra of TMC and TMCN, Table S1: Antibiotic susceptibility profile of clinical isolated MDR strains of A. baumannii.

Acknowledgments: Thanks to Ms. Chia-ying Chien and Jui-ting Chen of Precious Instrument Center (National Taiwan University) for the assistance in TEM and ESCA experiments. We also thank Ms. Ying-ying Wu of National Taiwan University of Science and Technology for the assistance in XRD experiments. Financial support for this work was provided by the Ministry of Science and Technology (MOST 105-2623-E-016-002-D \& MOST 105-2623-E-016-001- D), and the National Defense Medical Center (MAB-105-112 \& IPM-105-G8) of the Republic of China.

Author Contributions: J.-J. Young and T.-S. Chiueh conceived and designed the experiments; C.-Y. Chin performed the AgNPs formation experiments; K.-M. Cheng performed the Catalysis experiments; T.-Y. Chang, Y.-H. Chen and X.-A. Chen performed the antibacterial experiments; J.-R. Sun and T.-S. Chiueh performed the isolation and identification of MDR strains of A. baumannii; T.-Y. Chang and C.-C. Chen contributed materials analysis tools and analyzed the data; J.-J Young wrote the paper.

Conflicts of Interest: The authors declare no conflict of interest.

\section{References}

1. Rai, M.; Yadav, A.; Gade, A. Silver nanoparticles as a new generation of antimicrobials. Biotechnol. Adv. 27 2009, 76-83.

2. Sharma, V.K.; Yngard, R.A.; Lin, Y. Silver nanoparticles: Green synthesis and their antimicrobial activities. Adv. Colloid Interface Sci. 2009, 145, 83-93.

3. Abou, E.K.; Eftaiha ,A.; Al-Warthan, A.; Ammar, R. Synthesis and applications of silver nanoparticles. Arab. J. Chem. 2010, 3, 135-140.

4. Kirthi, A.V.; Rahuman, A.A.; Jayaseelan, C.; Karthik, L.; Marimuthu, S.; Santhoshkumar, T.; Venkatesan, J.; Kim, S.K.; Kumar,;G.; Kumar, S.; Rao, K. Novel approach to synthesis silver nanoparticles using plant pathogenic fungi Puccinia graminis. Mater. Lett. 2012, 81, 69-72.

5. Otari, S.V.; Patil, R.M.; Ghosh, S.J.; Thorat, N.D.; Pawar, S.H. Intracellular synthesis of silver nanoparticle by actinobacteria and its antimicrobial activity. Spectrochim. Acta A: Mol. Biomol. Spectrosc. 2015, 136, 1175-1180.

6. Rajana, R.; Chandran, K.; Harper, S.L.; Yun, S.I.; Kalaichelvan, P.T. Plant extract synthesized silver nanoparticles: An ongoing source of novel biocompatible materials. Ind. Crops. Prod. 2015, 70, 356-373.

7. Park, Y.; Hong, Y.N.; Weyers, A.; Kim, Y.S.; Linhardt, R.J. Polysaccharides and phytochemicals: a natural reservoir for the green synthesis of gold and silver nanoparticles. IET Nanobiotechnol. 2011, 5, 69-78.

8. Raveendran, P.; Fu, J.; Wallen, S.L. Completely "green" synthesis and stabilization of metal nanoparticles. J. Am. Chem. Soc. 2003, 125, 13940-13941.

9. M Valodkar,.; Bhadoria, A.; Pohnerkar, J.; Mohan, M.; Thakore, S. Morphology and antibacterial activity of carbohydrate-stabilized silver nanoparticles. Carbohydr. Res. 2010, 345, 1767-1773.

10. Venkatesham, M.; Ayodhya, D.; Madhusudhan, A.; Babu, N.; Veerabhadram, G. A novel green one-step synthesis of silver nanoparticles using chitosan: catalytic activity and antimicrobial studies. Appl. Nanosci. 2014, 4, 113-119.

11. Fanta, G.F.; Kenar, A.J.; Felker, F.C.; Byars, J.A. Preparation of starch-stabilized silver nanoparticles from amylose-sodium palmitate inclusion complexes. Carbohydr. Polym. 2013, 92, 260-268.

12. Bankura, K.P.; Maity, D.; Mollick, M.; Mondal, D.; Bhowmick, B.; Bain, M.K.; Chakraborty, A.; Sarkarc, J.; Acharyac, K.; Chattopadhyay, D. Synthesis, characterization and antimicrobial activity of dextran stabilized silver nanoparticles in aqueous medium. Carbohydr. Polym. 2012, 89, 1159-1165.

13. Zahrana, M.K.; Ahmeda, H.B.; El-Rafie, M.H. Alginate mediate for synthesis controllable sized AgNPs. Carbohydr. Polym. 2014, 111, 10-17. 
14. Abdel-Halim, E.S.; Al-Deyab, S.S. Utilization of hydroxypropyl cellulose for green and efficient synthesis of silver nanoparticles. Carbohydr. Polym. 2011, 86, 1615-1622.

15. Cheng, K.M.; Hung, Y.W.; Chen, C.C.; Liu, C.C.; Young, J.J. Green synthesis of chondroitin sulfate-capped silver nanoparticles: Characterization and surface modification. Carbohydr. Polym. 2014, 110, 195-202.

16. Xia, N.; Cai, Y.; Jiang, T.; Yao, J. Green synthesis of silver nanoparticles by chemical reduction with hyaluronan. Carbohydr. Polym. 2011, 86, 956-961.

17. Abid, J.P.; Wark, A.W.; Brevetm, P.F.; Girault, H.H. Preparation of silver nanoparticles in solution from a silver salt by laser irradiation. Chem. Commun. 2002, 7, 792-793.

18. Chen, P.; Song, L.Y.; Liu, Y.K. Synthesis of silver nanoparticles by $\gamma$-ray irradiation in acetic water solution containing chitosan. Radiat. Phys. Chem. 2007, 76, 1165-1168.

19. Alarcon, E.I.; Udekwu, K.; Skog, M.; Pacioni, N.L.; Stamplecoskie, K.G.; González-Béjar, M.; Polisetti, N.; Wickham, A.; Richter-Dahlfors, A.; Griffith, M.; Scaiano, J.C. The biocompatibility and antibacterial properties of collagen-stabilized, photochemically prepared silver nanoparticles. Biomaterials 2012, 33, 4947-4956.

20. Khan, A.; A. El-Toni, M.; Alrokayan, S.; Alsalhi, M.; Alhoshan, M.; Aldwayyan, A.S. Microwave-assisted synthesis of silver nanoparticles using poly-N-isopropylacrylamide/ acrylic acid microgel particles. Colloids Surf. A: Physicochem. Eng. Asp. 2011, 377, 356-360.

21. Yang, J.; Pan, J. Hydrothermal synthesis of silver nanoparticles by sodium alginate and their applications in surface-enhanced Raman scattering and catalysis. Acta Mater. 2012, 60, 4753-4758.

22. Reicha, F.M.; Sarhan, A.; Abdel-Hamid, M.I.; El-Sherbiny, I.M. Preparation of silver nanoparticles in the presence of chitosan by electrochemical method, Carbohydr. Polym. 2012, 89, 236-244.

23. Brown, P.K.; Qureshi, A.T.; Moll, A.N.; Hayes, D.J.; Monroe, W. Silver nanoscale antisense drug delivery system for photoactivated gene silencing. ACS Nano 2013, 7, 2948-2959.

24. Sarkar, K.; Banerjee, S.L.; Kundu, P.P.; Madras, G.; Chatterjee, K. Biofunctionalized surface-modified silver nanoparticles for gene delivery. J. Mater. Chem. B 2015, 3, 5266-5276.

25. Jazayeri, S.D.; Ideris, A.; Zakaria, Z.; Shameli, K.; Moeini, H.; Omar, A.R. Cytotoxicity and immunological responses following oral vaccination of nanoencapsulated avian influenza virus H5 DNA vaccine with green synthesis silver nanoparticles. J. Control. Release. 2012, 161, 116-123.

26. Sieval, A.B.; Thanoual, M.; Kotze, A.F.; Verhoef, J.C.; Brussee, J.; Junginger, H.E, Preparation and NMR characterization of highly substituted N-trimethyl chitosan chloride. Carbohydr. Polym. 1998, 36, 157-165.

27. Verheul, R.J.; Amidi, M.; van der Wal, S.; van Riet, E.; Jiskoot, W.; Hennink, W.E. Synthesis, characterization and in vitro biological properties of O-methyl free N,N,N-trimethylated chitosan. Biomaterials 2008, 29, 3642-3649.

28. Cardile, V.; Frasca, G.; Rizza, L.; Bonina, F.; Puglia, C.; Barge, A; Chiambretti, N.; Cravotto. G, Improved adhesion to mucosal cells of water-soluble chitosan tetraalkylammonium salts. Int. J. Pharm. 2008, 362, $88-92$.

29. Jia, Z.; Shen, D.; Xu, W. Synthesis and antibacterial activities of quaternary ammonium salt of chitosan. Carbohydr. Res. 2001, 333, 1-6.

30. Silhavy, T.J.; Kahne, D.; Walker, S. The bacterial cell envelope. Cold Spring Harb. Perspect Biol. 2010, 2, a000414.

31. Gottenbos, B.; Grijpma, D.W.; van der Mei, H.C.; Feijen, J.; Busscher, H.J. Antimicrobial effects of positively charged surfaces on adhering Gram-positive and Gram-negative bacteria. J. Antimicrob. Chemoth. 2001, 48, 7-13. 
32. Lee, K.J.; Browning, L.M.; Nallathamby, P.D.; Xu, X.H.N. Study of charge-dependent transport and toxicity of peptide-functionalized silver nanoparticles using zebrafish embryos and single nanoparticle plasmonic spectroscopy. Chem. Res. Toxicol. 2013, 26, 904-917.

33. Abbaszadegan, A.; Ghahramani, Y.; Gholami, A.; Hemmateenejad, B.; Dorostkar, S.; Nabavizadeh, M.; Sharghi, H. The effect of charge at the surface of silver nanoparticles on antimicrobial activity against Gram-positive and Gram-negative bacteria: A preliminary study. J. Nanomate. 2015, 205, 720654.

34. Rai, M.K.; Deshmukh, S.D.; Ingle, A.P.; A Gade,.K. Silver nanoparticles: the powerful nanoweapon against multidrug-resistant bacteria. J. Appl. Microbiol. 2012, 112, 841-852.

35. Singh, K.; Panghal, M.; Kadyan, S.; Chaudhary, U.; Yadav, J.P. Antibacterial activity of synthesized silver nanoparticles from Tinospora cordifolia against multi drug resistant strains of Pseudomonas aeruginosa isolated from burn patients. Nanomed. Nanotechnol. 2014, 5, 1000192.

36. Bokaeian, M.; Sheikh, M.; Hassanshahian, M.; Saeidi, S.; Sahraei, S. The antibacterial activity of silver nanoparticles produced in the plant Sesamum indicum seed extract: A green method against multi-drug resistant Escherichia coli. Int. J. Enteric Pathog. 2014, 2, e17928.

37. Behera, S.; Nayak, P.L. In vitro antibacterial activity of green synthesized silver nanoparticles using Jamun extract against multiple drug resistant bacteria. World J. Nano Sci. Technol. 2013, 2, 62-65.

38. Lara, H.H.; Ayala-Nunez, N.V.; Turrent, L.I.; Rodriguez Padilla, C. Bactericidal effect of silver nanoparticles against multidrug-resistant bacteria, World J. Microbiol. Biotechnol. 2010, 26, 615-621.

39. Eising, R.; Signori, A.M.; Fort, S.; Domingos, J.B. Development of catalytically active silver colloid nanoparticles stabilized by dextran. Langmuir 2011, 27, 11860-11866.

40. Mayrhofer, S.; Domig, K.J.; Mair, C.; Zitz, U.; Huys, G.; Kneifel, W. Comparison of broth microdilution, E test, and agar disk diffusion methods for antimicrobial susceptibility testing of Lactobacillus acidophilus group members. Appl. Environ. Microbiol. 2008, 74, 3745-3748.

41. Luber, P.; E Bartelt,.; Genschow, E.; Wagner, J.; Hahn, H. Comparison of broth microdilution, E test, and agar dilution methods for antibiotic susceptibility testing of Campylobacter jejuni and Campylobacter coli. J. Clin. Microbiol. 2003, 41, 1062-1068.

42. Hsieh, W.S.; Wang, N.Y.; Feng, J.A.; Weng, L.C.; Wu, H.H. Types and prevalence of carbapenem-resistant Acinetobacter calcoaceticus-Acinetobacter baumannii complex in Northern Taiwan. Antimicrob. Agents. Chemother. 2014, 58, 201-204.

43. Sun, J.R.; Perng, C.L.; J Lin,.C.; Yang, Y.S.; Chan, M.C.; Chang, T.Y.; Lin, F.M.; Chiueh, T.S. AdeRS combination codes differentiate the response to efflux pump inhibitors in tigecycline-resistant isolates of extensively drug-resistant Acinetobacter baumannii. Eur. J. Clin. Microbiol. Infect. Dis. 2014, 33, 2141-2147.

44. Kim, J.S.; Kuk, E.; Yu, K.; Kim, J.H.; Park, S.J.; Lee, H.J.; S Kim,.H.; Park, Y.K.; Hwang, Y.H.; Lee, Y.S; Jeong, D.H.; Cho, M.H. Antimicrobial effects of silver nanoparticles. Nanomed. 2007, 3 , 95-101.

45. Wan, G.; Ruan, L.; Yin, Y.; T Yang,.; Ge, M.; Cheng, X. Effects of silver nanoparticles in combination with antibiotics on the resistant bacteria Acinetobacter baumannii, Int. J. Nanomed. 2016, 11, 3789-3800.

46. P Nascente,.S.; A Meinerz,.R.M.; de Faria, R.O.; Schuch, L.F.D.; Meireles, M.C.A.; de Mello, J.R.B. CLSI broth microdilution method for testing susceptibility of malassezia pachydermatis to thiabendazole. Braz. J. Microbiol. 2009, 40, 222-226.

(C) 2017 by the authors. Licensee Preprints, Basel, Switzerland. This article is an open access article distributed under the terms and conditions of the Creative Commons by Attribution (CC-BY) license (http://creativecommons.org/licenses/by/4.0/). 